\title{
Cetoacidose diabética - de volta aos conceitos básicos
}

\author{
Diabetic ketoacidosis - revisiting the basic concepts
}

\begin{abstract}
Durval Damiani*
Freqüentemente se diz que a introdução de insulina na prática clínica ocasionou uma dramática diferença na mortalidade resultante do coma diabético. A afirmativa é válida no sentido de que, até 1922, o coma diabético era uniformemente fatal. No entanto, até a década de 50, a mortalidade por cetoacidose diabética era da ordem de 30 a $50 \%$. Muitos desses pacientes não tinham a causa de sua morte esclarecida por necrópsia e podem ter morrido por hipocalemia, uma complicação que só foi reconhecida em 1946. Naquele ano, no Jornal da American Medical Association, Jacob Holler descreveu um paciente que desenvolveu paralisia respiratória após 12 horas de tratamento e, após várias horas no "pulmão de aço", foi curado por infusão de potássio. Nos cinco anos que se seguiram ao trabalho de Holler, houve muitos relatos de óbitos devidos a hipocalemia e verificava-se que os clínicos eram muito temerosos de administrar potássio por injeção endovenosa. Num editorial do Lancet, o autor sugeria que "devido aos efeitos assustadores de injeções endovenosas de potássio, os clínicos estavam relutantes em crer que a falta desse mine-

a década de $70^{4,5}$. O edema cerebral, a complicação mais temível da CAD, ocorre em 1 a $2 \%$ dos pacientes, é mais freqüente em crianças e adolescentes e eleva a mortalidade para cifras em torno de $30 \%$.

A questão básica é que o paciente chega a um estado de CAD depois de um período de deficiência insulínica, que caracteriza o diabetes mellitus tipo 1. O organismo põe em ação uma série de mecanismos de defesa para fazer frente a um quadro de grave perda hídrica, que pode culminar com choque hipovolêmico, acidose metabólica com seu componente de acúmulo de cetoácidos (ácidos cetoacético e b hidróxi-butírico, resultantes da degradação lipídica) e de ácido lático, e uma hipertonicidade sérica derivada dos freqüentemente altos níveis de glicemia (se bem que este componente possa não ser tão importante, já que temos situações em que a glicemia não está importantemente elevada e estamos com CAD). No momento em que se inicia o tratamento, pode haver uma certa "pressa" na correção dos distúrbios metabólicos presentes e, nesse ponto, o médico pode ocasionar ral pudesse ser causa de problema, exceto em condições muito raras como a paralisia periódica familial ${ }^{1}$.

Apesar de controvérsias em termos de definição e tratamento, a cetoacidose diabética (CAD) é uma emergência médica cuja abordagem requer o conhecimento de princípios básicos de terapia intensiva e de fisiologia. Cerca de $25 \%$ dos pacientes com sua primeira descompensação diabética podem apresentar-se em CAD, o que deve fazer todo médico que trabalha em serviços de emergência ter este diagnóstico na sua "lista mental" de causas possíveis de desidratação grave, coma e acidose metabólica. Nos pacientes já sabidamente diabéticos, um quadro infeccioso, a omissão da administração de insulina, bem como problemas psicossociais, freqüentemente envolvendo disfunções familiares, são a causa da descompensação, o que chama a atenção para o desenvolvimento de estratégias preventivas, que devem ser tomadas pelo médico que acompanha o paciente no seu quadro de diabetes, quer seja o Pediatra, o Clínico ou o Endocrinologista2 2 .

Mais de 100.000 pacientes são hospitalizados anualmente nos Estados Unidos da América por $\mathrm{CAD}^{3}$. Ainda hoje, a mortalidade resultante de CAD é da ordem de 5 a $10 \%$ e tem ficado "teimosamente" nesses patamares desde

mais malefícios do que benefícios ao paciente. Andar rápido não significa necessariamente ter pressa!

O primeiro passo diante de um paciente em CAD é garantir-lhe uma condição básica de sobrevida, com preservação da permeabilidade de suas vias aéreas, sua respiração (que neste momento é acidótica) e sua condição circulatória. Portanto, a infusão inicial de fluidos (sobre a natureza dos quais já houve muita polêmica, mas hoje há razoável acordo no sentido de que se pode usar soro fisiológico) visa a garantir uma condição circulatória básica eficiente, e a infusão rápida de $20 \mathrm{ml} / \mathrm{kg}$, que pode ser repetida até que se consiga uma condição circulatória razoavelmente boa, passa a ser fundamental. No entanto, a partir daí, como é didaticamente exposto no artigo de Collet-Solberg neste número do Jornal de Pediatria, a infusão de volume, repondo suposta perda inicial de $10 \%$ do peso, deve ser extremamente cuidadosa. Reposições intempestivas podem levar à complicação mais temida desse quadro que é o edema cerebral. A modificação da tonicidade dos vários compartimentos orgânicos (espaço intravascular, espaço intracelular, interstício) deve ser o mais "suave" possível, evitando grandes movimentos de fluidos de um compartimento para outro: quando se baixa muito rapidamente a tonicidade intravascular, ocorre um fluxo de líqüido para o intracelular (cérebro) que cria a condição do edema cerebral.
\end{abstract}

\footnotetext{
* Professor Livre-Docente da Unidade de Endocrinologia Pediátrica, Instituto da Criança, Hospital das Clínicas da Faculdade de Medicina da Universidade de São Paulo.
} 
Um outro aspecto que não pode ser esquecido é que o início da administração de insulina começa a bloquear os processos que conduziram o paciente ao quadro de CAD, de modo que, a partir da infusão de insulina, passamos a nos preocupar com a taxa de queda da glicemia (que também não deve ser rápida) e com as correções dos demais desequilíbrios que se instalaram, como a depleção de potássio, já citada no artigo de Holler em 1946, e a acidose metabólica. Aliás, com relação à acidose metabólica, tem sido difícil convencer os profissionais envolvidos no atendimento do paciente diabético de que a administração de bicarbonato de sódio é mais lesiva do que benéfica ao paciente. Silink afirma textualmente: “...evite o uso de bicarbonato de sódio a menos que a acidose esteja interferindo com a contratilidade miocárdica"6. Green e col., analisando 147 admissões por CAD, observaram que o grupo que não recebeu bicarbonato de sódio, incluindo 9 pacientes com $\mathrm{pH}$ menor ou igual a 7,00 (um deles com $\mathrm{pH}$ de 6,73!), teve ótima evolução e, comparando o grupo que recebeu com o que não recebeu bicarbonato, os autores constataram que a frequiência de complicações não foi diferente. Em sua conclusão, eles ressaltam que "não houve evidência de que a administração de bicarbonato melhorasse a evolução de crianças com CAD grave. A taxa de recuperação metabólica e de complicações foi semelhante nos dois grupos, e a hospitalização era mais prolongada no grupo com bicarbonato. Nós concluímos que a administração de bicarbonato é desnecessária e potencialmente desvantajosa na CAD grave"7.

Em nosso serviço, temos evitado sistematicamente o uso de bicarbonato de sódio e temos observado a resolução do quadro de acidose metabólica, já que estamos repondo volume e gradualmente normalizando as condições circulatórias (o que diminui o componente de acidose lática); estamos administrando insulina (que bloqueia a lipólise e promove a eliminação progressiva dos corpos cetônicos acumulados); e estamos repondo potássio, que invariavelmente está depletado (o K $\mathrm{K}^{+}$acaba saindo da célula em troca com $\mathrm{H}^{+}$, o que mascara o nível sérico, que pode estar normal mas a depleção é intracelular e deve haver reposição). Portanto, não administrar bicarbonato não quer dizer que não estejamos tratando a acidose metabólica.
Como o edema cerebral é a complicação mais temida, qualquer modificação do sensório, hipertensão arterial com bradicardia, cefaléia, vômitos, alterações visuais, edema de papila, convulsões, dentre outros sinais e sintomas, deve chamar imediatamente a atenção para a possibilidade dessa complicação, e as medidas terapêuticas (basicamente administração de manitol) devem ser instituídas sem demora, pois dessa rapidez, dependerá a evolução desse paciente.

A questão básica apresentada no artigo de Collet-Solberg diz respeito à maneira de se infundir fluidos e como trabalhar com o sistema de "duas soluções salinas". Apesar de o autor afirmar que "... o objetivo desta revisão não é mostrar um novo regime terapêutico para o tratamento da CAD, mas sim mostrar uma maneira de se fazer o controle mais prático e que pode ser adaptado para cada serviço", trata-se de uma exposição muito clara e didática para o tratamento da CAD. Sugere-se que cada Serviço, calcado nos princípios básicos delineados, implemente seus protocolos, com o objetivo maior de reduzir a morbi-mortalidade que continua sendo intoleravelmente elevada nesses casos.

\section{Referências bibliográficas}

1. Tattersall RB. A paper which changed clinical practice (slowly). Jacob Holler on potassium deficiency in diabetic acidosis (1946). Diabet Med 1999; 12:978-84.

2. Kaufman FR, Halvorson M. The treatment and prevention of diabetic ketoacidosis in children and adolescents with type 1 diabetes mellitus. Pediatr Ann 1999; 9:576-82.

3. Levetan CS, Passaro MD, Jablonski KA, Ratner RE. Effect of physician specialty on outcomes in diabetic ketoacidosis. Diabetes Care 1999; 11:1790-5.

4. Wagner A, Risse A, Brill HL, Wiehnausen WV, Rottmann M, Sondern K, Angelkort B. Therapy of severe diabetic ketoacidosis. Zero-mortality under very-low-dose insulin application. Diabetes Care 1999; 5:674-7.

5. Kitabchi AE, Wall BM. Management of diabetic ketoacidosis. Am Fam Physician 1999; 60:455-64.

6. Silink M. Practical management of diabetic ketoacidosis in childhood and adolescence. Acta Paediatr 1998; Suppl 425:63-6.

7. Green SM, Rothrock SG, Ho JD, Gallant RD, Borger R, Thomas TL, et al. Failure of adjunctive bicarbonate to improve outcome in severe pediatric diabetic ketoacidosis. Ann Emerg Med 1998; $1: 41-8$.

\title{
O crescimento de crianças indígenas
}

\author{
The growth of indian children
}

\section{Dioclécio Campos Júnior*}

\begin{abstract}
A promoção da saúde das crianças indígenas é um objetivo cuja prioridade parece alcançar adesão consensual na atualidade brasileira.
\end{abstract}

* Professor Titular de Pediatria da Fac. de Medicina da Univ. de Brasília.
Trata-se de um compromisso que decorre do conhecimento crescente das condições sofríveis em que nascem, vivem e morrem os povos nativos do país, sobreviventes de quinhentos anos de penosa resistência ao processo colonizador que lhes roubou territórios, dizimou populações, 